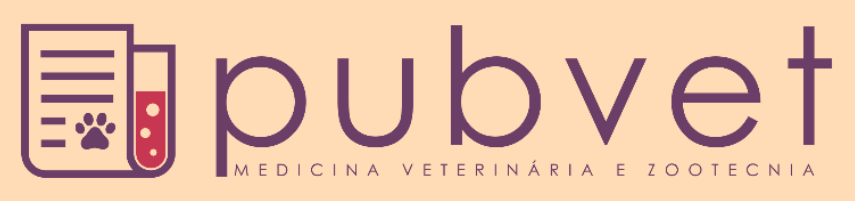

ISSN 1982-1263

https://doi.org/10.31533/pubvet.v13n3a286.1-9

\title{
Urolitíase em Porquinho-da-Índia (Cavia porcellus): Relato de Caso
}

\author{
Yara Tayna Sato Pimenta ${ }^{\bullet}{ }^{*}$, Renato Dalcin Segala ${ }^{\bullet}{ }^{\bullet}$, Maria Carolina Gonçalves \\ Pita $^{3}{ }^{\circ}$, Breno Aguiar Salzedas ${ }^{\circ}$, Denise Macedo Lopes $^{4}{ }^{\circ}$, Samara Oliveira dos \\ Santos $^{5}{ }^{\circ}$, Rafael Barbosa Cangussu ${ }^{1}$ \\ ${ }^{1}$ Graduanda de Medicina Veterinária da Universidade de Guarulhos - Brasil. \\ ${ }^{2}$ Docente na Universidade de Guarulhos - Departamento de Clínica Cirúrgica, Guarulhos - SP, Brasil. \\ ${ }^{3}$ Médica Veterinária e Doutora em Ciência Animal. \\ ${ }^{4}$ Aprimorando da Universidade de Guarulhos, Departamento de Laboratório Clínico, Guarulhos - SP, Brasil. \\ ${ }_{5}^{5}$ Aprimoranda do departamento de anestesiologia, Universidade de Guarulhos, SP, Brasil. \\ * Autor para correspondência, E-mail: yara_tayna@hotmail.com
}

Resumo. Urolitíase é uma doença comum em porquinho-da-índia, caracterizada pela presença de cálculos em qualquer segmento do trato urinário, geralmente os cálculos ou urólitos são encontrados na bexiga e uretra, na maioria formada por base no cálcio (Carbonato de Cálcio e Fosfato de Cálcio). As fêmeas, principalmente as mais velhas com idade superior a quatro anos são as mais acometidas. Os sinais clínicos variam de acordo com o local e a quantidade que estes cálculos se encontram. O diagnóstico é com exame ultrassonográfico e radiográfico e são necessários exames complementares para auxiliar no prognóstico. O tratamento de eleição é cirúrgico, podendo ser por cistoscopia em fêmeas, bem como um tratamento suporte, além de orientação do proprietário sobre dietas e manejo, objetivando-se diminuir incidência de recidivas. $\mathrm{O}$ presente trabalho faz $\mathrm{o}$ relato de caso clínico de um porquinho-da-índia, fêmea, 4.8 anos, atendida na Clínica Escola Veterinária da Universidade de Guarulhos, diagnosticada clinicamente como formação tumoral sem mobilidade em região perivulvar, durante a cirurgia removeu-se um urólito da região por uretrotomia.

Palavras chave: uretrotomia, urinário, urólito

\section{Urolithiasis in guinea pig (Cavia Porcellus): Case Report}

Abstract. Urolithiasis is a common disease characterized by the presence of stones in any segment of the urinary tract that affects guinea pig. Usually the calculus or uroliths are located in the bladder and urethra, mostly calcium-based (Calcium Carbonate and Calcium Phosphate). Females, especially those older than 4 years, are more affected. The clinical signs vary according to the location and quantity these calculi get together. The diagnosis is made with ultrasonography and radiographic with additional examinations that are required to assist the prognosis. The treatment is by surgery, which may be done by cystoscopy in females as well as a support treatment, besides owner orientation about diets and management, focusing on reducing incidence relapse. This paper reports a guinea pig clinical case, female, 4.8 years old, attended at the Veterinary School Clinic of the Universidade de Guarulhos, clinically diagnosed as tumor formation without mobility on a perivulve region, which a urolith were removed of the region by urethrotomy during surgery.

Key words: urethrotomy, urinary, urolith 


\title{
Urolitiasis en cuyes (Cavia Porcellus): Relato de Caso
}

\begin{abstract}
Resumen. La urolitiasis es una enfermedad común en los cuyes, caracterizada por la presencia de cálculos en cualquier segmento del tracto urinario, generalmente los cálculos o urolitos se encuentran en la vejiga y la uretra, en su mayoría formados por base en el calcio (Carbonato de Calcio y Fosfato de calcio). Las hembras, principalmente las mayores con edad superior a cuatro años son las más acometidas. Los signos clínicos varían según el lugar y la cantidad de estos cálculos. El diagnóstico es con examen ultrasonográfico y radiográfico y son necesarios exámenes complementarios para auxiliar en el pronóstico. El tratamiento de elección es quirúrgico, pudiendo ser por cistoscopia en hembras, así como un tratamiento soporte, además de orientación del propietario sobre dietas y manejo, con el objetivo de disminuir la incidencia de recidivas. El presente trabajo hace el relato de caso clínico de un cuye, hembra, de 4.8 años, atendida en la Clínica Escuela Veterinaria de la Universidad de Guarulhos, diagnosticada clínicamente como formación tumoral sin movilidad en región perivulvar, durante la cirugía se retiró un urolito de la región por uretrotomía.
\end{abstract}

Palabras clave: uretrotomía, urinario, urolitos

\section{Introdução}

A urolitíase é uma doença, bem documentada, do sistema urogenital em animais domésticos e humanos, vem sendo relatada cada vez mais em espécies selvagens, tanto cativas como em estado selvagem (Dias, 2016). O termo urolitíase refere-se à presença de cálculos em qualquer parte do trato urinário, frequentemente encontrados na uretra e bexiga. A maioria dos urólitos tem como base o cálcio, como o carbonato de cálcio e fosfato de cálcio, enquanto o oxalato de cálcio é mais raro (Latney \& Donnelly, 2013). É uma doença de caráter crônico, comumente diagnosticada em herbívoros (Vella, 2012). A urolitíase é um problema urinário comum em cobaias velhas (> 4 anos), acometendo mais as fêmeas $75 \%$, do que os machos com uma incidência mundial de $10 \%$ (Latney \& Donnelly, 2013). A etiologia desses cálculos não está clara. Os autores indicam diversas causas como fatores para a precipitação e formação de urólitos. Destacando-se principalmente a nutrição incorreta (Furlaneto, 2017; Gonçalves, 2014).

Os sinais clínicos observados são dependentes da localização do urólito bem como de seu tamanho, podendo incluir estrangúria, disúria, hematúria, anúria, poliúria, anorexia, dor abdominal (postura curvada), vocalização durante a micção, polaquiúria e letargia (Gonçalves, 2014; Latney \& Donnelly, 2013). O diagnóstico de urolitíase em roedores é baseado nos exames radiográfico e ultrassonográfico. Análise de urina, exames bioquímicos e sangue (Gonçalves, 2014).

O tratamento de eleição para urolitíase é a remoção cirúrgica, através de uretrotomia, cistotomia ou no caso de machos, pode ser indicada amputação do pênis (Furlaneto, 2017). Em fêmeas, a remoção de urólito por cistoscopia uretral pode ser realizada, que é viável apenas para pedras que não são maiores de diâmetro do que a uretra (Latney \& Donnelly, 2013).

\section{Relato de caso}

Um porquinho-da-índia (Cavia porcellus), fêmea, pelagem tricolor, com 4,8 anos de idade, pesando $1,15 \mathrm{~kg}$ foi atendido na Clínica Escola Veterinária da Universidade de Guarulhos, no dia 15 de fevereiro de 2017. Ao atendimento clínico o proprietário relatou que adquiriu ainda filhote, tinha como contactante outro animal da mesma espécie, ficava em gaiola e andava pouco, por vezes ficava solta no piso de cerâmica, nulípara, estava alimentando-a com nutricobaia até seis meses anteriores. Porém havia parado com a alimentação específica e introduzido ração para coelhos, cenoura, melão, banana, escarola, almeirão e capim. Fazia suplementação de vitamina C (Redoxon ${ }^{\circledR}$ ), na dose correta.

Na queixa principal relatou que há um mês e meio, paciente começou a vocalizar e também encontrou um aumento de volume em região perivulvar do tamanho de uma ervilha. Deu uma gota de Cetoprofeno (Profenid ${ }^{\circledR}$ ) por um dia. Notou-se ao exame clínico pododermatite com aumento de volume, hiperemia, pontos pequenos de necrose e edema em ambas as patas, principalmente em 
membros torácicos. Também apresentava na inspeção, um aumento de volume de consistência firme em região inguinal (cranial à vulva), medindo aproximadamente dois centímetros, solto nas laterais e preso ao assoalho da vagina, sem calor, rubor e dor leve à palpação (Figura 1). Não apresentou outras alterações, mucosas estavam normocoradas, hidratação adequada e linfonodos não reativos, a auscultação pulmonar sem alterações da normalidade. Foi solicitado hemograma, radiografia (com projeções latero-lateral e ventro-dorsal do toráx), ultrassonografia abdominal e indicado procedimento cirúrgico para retirada de tumores. Na radiografia pulmonar os campos pulmonares estavam sem alterações, hemograma normal (Tabela 1), na ultrassonografia abdominal (Tabela 2) não havia nada digno de nota, exceto em região abdominal caudal subcutâneo aumento de volume de $0,9 \mathrm{~cm}$ com produtos de reforço acústico e em recessos pélvicos foram observadas mineralizações, porém na vesícula urinária havia apenas sedimentos e/ou aumento da celularidade, sem sinais de litíase. Após a realização dos exames, a paciente foi encaminhada para o procedimento cirúrgico.

Realizou-se a uretrotomia para a remoção do cálculo, no dia oito de março de 2017. Primeiramente seria realizada uma nodulectomia por suspeita de neoplasia; porém, na cirurgia descobriu que se tratava de um urólito que estava na porção caudal da uretra. Foi feito o preparo do paciente, com tricotomia da região perivulvar, anestesia, posicionamento do paciente em decúbito dorsal e antissepsia da pele.

A medicação pré-anestésica utilizada foi Midazolam $2 \mathrm{mg} / \mathrm{kg}$ intramuscular e Cloridrato de Cetamina $20 \mathrm{mg} / \mathrm{kg}$ intramuscular. O paciente foi mantido em plano anestésico por anestesia inalatória na máscara com Isofluorano e no pós-operatório foi utilizado Cloridrato de Tramadol na dose de 7,5 mg/kg intramuscular. Incisou-se a pele na região perineal cutânea de aumento de volume, percebeu-se que o aumento de volume era referente à uretra, portanto, foi realizada a incisão na uretra porção caudal próximo a desembocadura da vagina (uretrotomia) para visualizar e retirar o cálculo, após esse procedimento, removeu-se o cálculo com pinça anatômica e foi feito sutura invaginante com fio Vicryl ${ }^{\circledR}$ 3-0 Ag com ponto simples separado. Foi retirado um urólito de $2,2 \mathrm{~cm}$ (Figura 2).Foi prescrito para o pós- cirúrgico Enrofloxacina (Baytril ${ }^{\circledR}$ ) 7,5 mg/BID/7 dias, Meloxicam 0,25 mg/SID/2 dias, Cloridrato de Tramadol Gotas 3 gotas/BID/3 dias e limpeza com gaze e solução fisiológica e após aplicar iodo povidine na região da ferida cirúrgica com auxílio de uma gaze, a cada 12 horas, até novas recomendações.

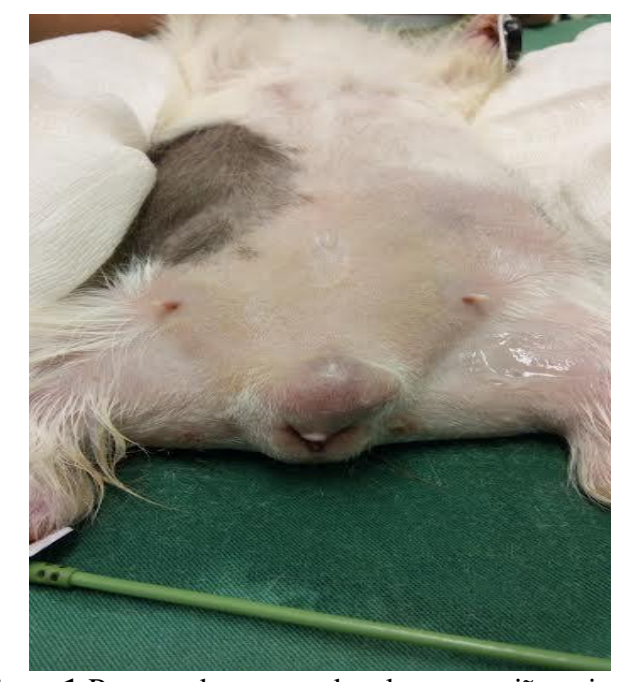

Figura 1. Presença de aumento de volume na região perivulvar.

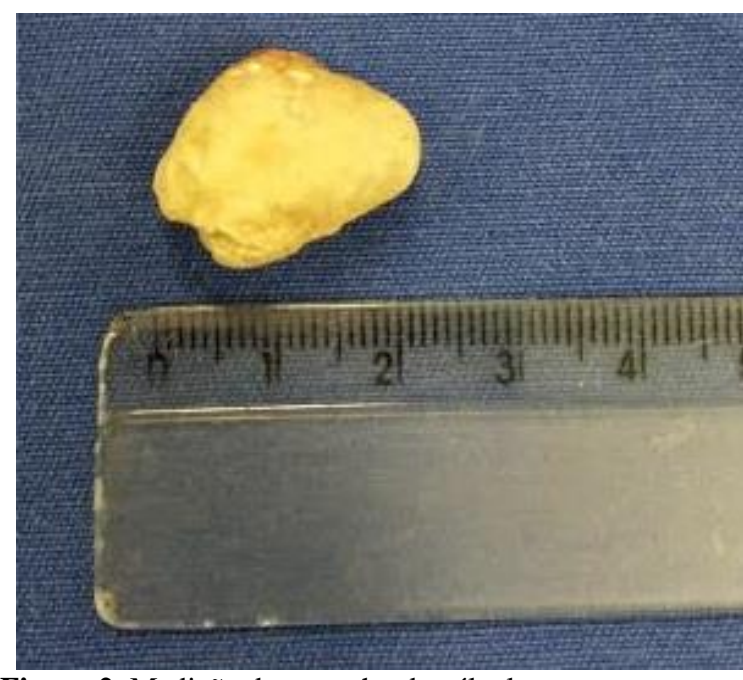

Figura 2. Medição do tamanho do cálculo.

Retornou no dia 15 de março de 2017 para retirada de pontos, peso $1,05 \mathrm{~kg}$. A pododermatite estava pior em membro torácico direito, no local dos pontos cirúrgicos havia uma pequena abertura, assemelhando-se a uma fístula, sem odor de urina e pelos úmidos na região circundante. Retornou 
novamente no dia 5 de abril de 2017. O paciente apresentava-se cianótico, com hidratação adequada, mucosa ocular hipocorada, tremores, proprietária referiu que há 48 horas está mais quieta, nega diarreia, tinha sido administrado pelo proprietário três gotas de Metoclopramida (Plasil@), três gotas de Cetoprofeno, Simeticona $\left(\operatorname{Luftal}^{\circledR}\right)$ e probiótico. Pesando $0,85 \mathrm{~kg}$, convulsões, temperatura $35^{\circ} \mathrm{C}$. $\mathrm{Na}$ tentativa de reestabelecimento do paciente, não se obteve sucesso. Choque e óbito. Foi realizada necrópsia e a causa mortis foi choque toxêmico causado por nefrite insterticial.

\section{Resultados}

Na radiografia pulmonar os campos pulmonares estavam sem alterações, hemograma préoperatório normal (Tabela 1, 2 e 3).

Tabela 1. Hemograma pré-operatório - Eritrograma de de um porquinho-da-índia, fêmea, 4.8 anos, atendida na Clínica Escola Veterinária da Universidade de Guarulhos

\begin{tabular}{lcc}
\hline & Resultados & Valores de Referência \\
\hline Hemácias & 3.9 milhões $/ \mathrm{mm}^{3}$ & 3,2 a 8,0 \\
Hemoglobina & $13.9 \mathrm{~g} / \mathrm{dl}$ & 10 a 17,2 \\
Hematócrito & $33 \%$ & 32 a 50 \\
Proteínas Totais & $6,2 \mathrm{~g} / \mathrm{dl}$ & 4,5 a 7,5 \\
Eritoblastos & $0 / 100$ leucócitos & Até $1 \%$ \\
\hline
\end{tabular}

Adaptado: Eurell \& Frappier (2012).

Tabela 2. Hemograma pré-operatório - Leucograma de um porquinho-da-índia, fêmea, 4.8 anos, atendida na Clínica Escola Veterinária da Universidade de Guarulhos

\begin{tabular}{lcccc}
\hline & \multicolumn{2}{c}{ Resultados } & \multicolumn{2}{c}{ Valores de Referência } \\
\cline { 2 - 5 } & Relativo $(\%)$ & Absoluto & Relativo & Absoluto \\
\hline Leucócitos Totais & 100 & 7.300 & - & 5.700 a 18.000 \\
Metamielócitos & 0 & 0 & 0 & 0 \\
Bastonetes & 0 & 0 & 20 a 60 & 0 \\
Segmentados & 52 & 3.796 & 0 a 7 & 0 a 1.260 \\
Eosinófilos & 3 & 219 & 0 a 3 & 0 a 540 \\
Basófilos & 0 & 0 & 30 a 80 & 1.710 a 14.400 \\
Linfócitos Típicos & 45 & 0 & 0 \\
Linfócitos Atípicos & 0 & 0 & 1 a 20 & 57 a 3.600 \\
Monócitos & 0 & 0 & 285 &
\end{tabular}

Obs: Morfologia Celular Normal. Pesquisa de Hemoparasitos: Pesquisa Negativa. Adaptado: Eurell \& Frappier (2012).

Tabela 3. Hemograma pré-operatório - Plaquetas de de um porquinho-da-índia, fêmea, 4.8 anos, atendida na Clínica Escola Veterinária da Universidade de Guarulhos

\begin{tabular}{lc}
\hline Resultado & Valor de Referência \\
\hline $747.000 / \mathrm{mm}^{3}$ & 250.000 a $850.000 / \mathrm{mm}^{3}$ \\
\hline Obs: Plaqu
\end{tabular}

Obs: Plaquetas normais em morfologia. Adaptado: Eurell \& Frappier (2012).

Na ultrassonografia abdominal (Quadro 1) não havia nada digno de nota, exceto em região abdominal caudal subcutâneo tumor de $0,9 \mathrm{~cm}$ com produtos de reforço acústico e em recessos pélvicos foram observadas mineralizações, porém na vesícula urinária haviam apenas sedimentos e/ou aumento da celularidade, sem sinais de litíase.

Foi realizada necropsia para auxiliar no diagnóstico e determinar a causa mortis, os conjuntos foram descritos na tabela a seguir (Quadro 2), que demonstra todas as lesões encontradas no exame de histopatológico. 
Na necrópsia observou-se na inspeção externa foi visualizado a presença de lesões ulceradas com crostas melicéricas compatíveis com pododermatite (Figura 6A) nos quatro membros.

Quadro 1. Laudo do Exame Ultrassonográfico pré-operatório de um porquinho-da-índia, fêmea, 4.8 anos, atendida na Clínica Escola Veterinária da Universidade de Guarulhos

Bexiga urinária: Repleção adequada, apresentando sua forma mantida, paredes normoespessas, conteúdo anecogênico, com moderada quantidade de sedimento ecogênico (aumento e/ou alteração de celularidade). Não há sinais de litíases.

Útero: Corpo e cornos uterinos com dimensões preservadas $0,5 \mathrm{~cm}$, paredes finas e regulares, dimensões preservadas, anecóicos, medindo $0,98 \mathrm{~cm}$ o esquerdo e $1,4 \mathrm{~cm}$ o direito (com dimensões mais evidentes), em maior eixo.

Rins: Simétricos, apresentando dimensões normais (Rim Esquerdo: 2,10 e Rim Direito: 2,48 cm, no maior eixo), topografia habitual, contornos regulares, arquitetura e ecogenicidade de corticais normais. Definição córtico-medular mantida.

Observamos mineralizações em recessos pélvicos.

Fígado: Dentro dos limites do gradil costal, apresentando contornos regulares, bordas finas, parênquima homogêneo e ecogenicidade normal. Arquitetura vascular com trajeto e calibre preservados. Vesícula Biliar: Repleta, com paredes finas e conteúdo anecogênico homogêneo.

Estômago: Paredes normoespessas, medindo $0,27 \mathrm{~cm}$, estratificação parietal mantida (nas regiões passíveis de visibilização) e conteúdo gasoso luminal.

Alças intestinais: Distribuição topográfica normal, paredes normoespessas, estratificação parietal mantida. Ausências de imagens sugestivas de corpo estranho (com características, dimensões e localização acessíveis ao ultrassom neste momento). Ausência de sinais de obstrução. Ausência de sinais sugestivos de alteração em motilidade.

Baço: Apresentando dimensões normais, contornos regulares, parênquima homogêneo e ecogenicidade mantida.

Pâncreas: Sem evidências de alterações ultrassonográficas em região habitual.

Adrenal: Esquerda com forma mantida, homogênea, medindo $0,3 \mathrm{~cm}$ de espessura em polo caudal. A Direita não foi caracterizada.

Linfadenomegalias e líquido livre: Não foram observados no momento do exame.

OBS: Em região abdominal caudal, em subcutâneo, observa-se aumento de volume medindo $0,90 \mathrm{~cm}$ - produtor de reforço acústico (a esclarecer). Caso o clínico considere necessário, sugere-se citologia aspirativa como exame complementar.

Quadro 2. Achados da Descrição Histopatológica e Macroscópica (Anatomopatológico) - Descrição das lesões encontradas nos órgãos no exame de histopatológico post-morten. Exame realizado para identificar a causa que levou ao óbito através da observação das lesões macroscópicas e microscópicas em porquinho-da-índia, fêmea, 4.8 anos, atendida na Clínica Escola Veterinária da Universidade de Guarulhos

\begin{tabular}{|l|l|}
\hline Conjunto & Descrição dos Órgãos no Histopatológico \\
\hline $1^{\circ}$ & $\begin{array}{l}\text { Sistema Respiratório com pulmões avermelhados com áreas focais mais escuras e armados sugestivos de } \\
\text { congestão moderada, hemorragia e edema; } \\
\text { Sistema Cardiovascular com coração apresentando coágulo cruórico em ventrículo esquerdo, além de } \\
\text { intensa embebição hemoglobínica do endotélio mural e valvar, sem evidências de lesões aparentes (Figura 3). }\end{array}$ \\
\hline $2^{\circ}$ & $\begin{array}{l}\text { No Sistema Linfohemopoiético: Baço apresentava pequenos focos avermelhados escuros por todo o } \\
\text { parênquima (Congestão moderada) (Figura 4). }\end{array}$ \\
\hline $3^{\circ}$ & $\begin{array}{l}\text { Em Sistema Digestório o estômago também apresentava áreas com embebição hemoglobínica e o fígado } \\
\text { avermelhado escuro (congestão moderada). }\end{array}$ \\
\hline $4^{\circ}$ & $\begin{array}{l}\text { Fígado com presença de infiltrado linfoplamocitário no espaço porta (Hepatite periportal multifocal), } \\
\text { vacuolização em hepatócitos (Esteatose), presença de grande quantidade de hemácias nos sinusóides e nos } \\
\text { vasos sanguíneos de maior diâmetro (Congestão) (Figura 5). }\end{array}$ \\
\hline $5^{\circ}$ & $\begin{array}{l}\text { No Sistema Urinário, os rins estavam avermelhados tanto em zona cortical e medular (Congestão } \\
\text { moderada), a uretra apresentava um orifício de 2 milímetros de diâmetro com comunicação em região } \\
\text { púbica - Fístula uretral. } \\
\text { Na descrição microscópica os rins apresentavam células tubulares vacuolizadas (sugerindo degeneração } \\
\text { hidrópica), cápsula de Bowman nos glomérulos e da parede dos capilares glomerulares, presença de alguns } \\
\text { corpúsculos glomerulares dilatados formando estruturas císticas, com pequenos focos de proliferação } \\
\text { fibroblástica. Múltiplos focos de infiltrado de células inflamatórias, predominantemente mononucleares } \\
\text { (Nefrite intersticial crônica proliferativa com focos de fibrose); } \\
\text { Adrenal sem anormalidades; } \\
\text { Vesícula urinária com presença de múltiplos focos de infiltrado de células inflamatórias mononucleares, } \\
\text { predominantemente linfócitos (Cistite Crônica Linfocitária Multifocal); }\end{array}$ \\
\hline Inspeção externa & $\begin{array}{l}\text { Membro anterior direito com presença de lesão ulcerada com crostas melicéricas - Pododermatite. } \\
\text { Causa mortis }\end{array}$ \\
\hline \begin{tabular}{l} 
Moléstia principal sendo referida como Nefrite Intersticial Crônica a causa mortis como choque toxêmico. \\
\hline
\end{tabular} \\
\hline
\end{tabular}




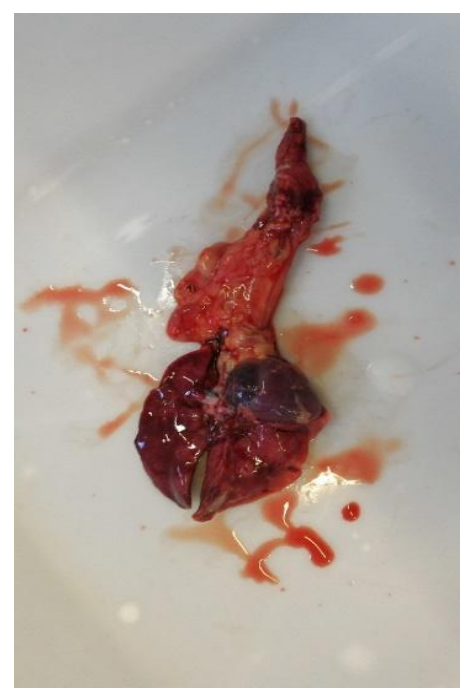

Figura 3. Primeiro Conjunto: Língua, traquéia, tireóides, esôfago, pulmões e coração.

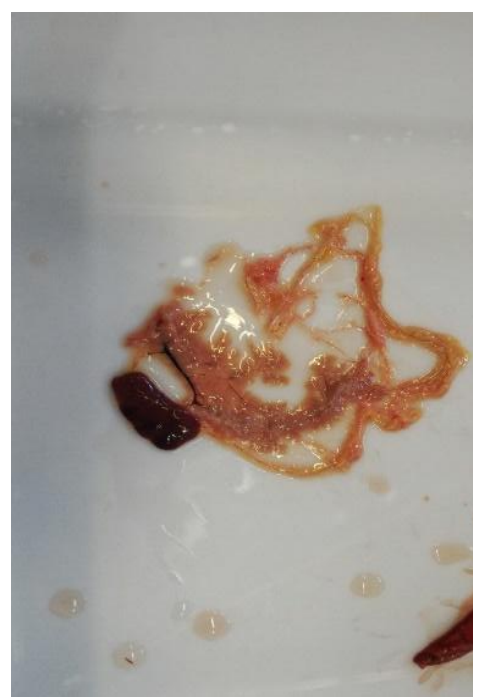

Figura 4. Segundo Conjunto: Baço e omento.

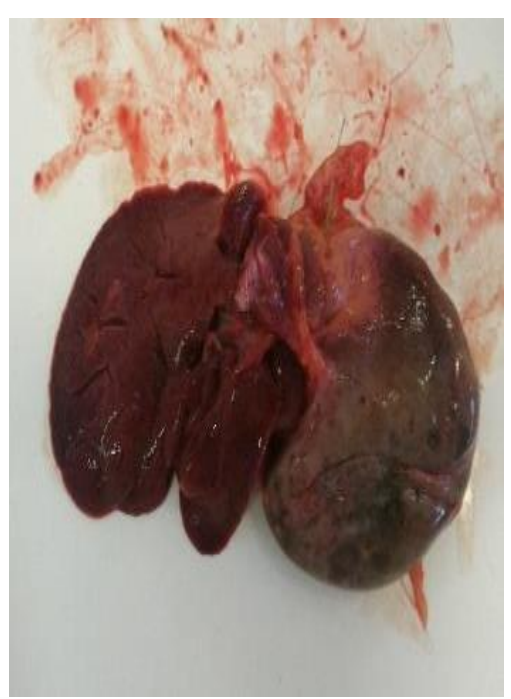

Figura 5. Quarto Conjunto: Fígado, estômago, pâncreas e vesícula biliar.

Notou-se fístula de dois milímetros de diâmetro, fazendo uma comunicação da uretra com a região púbica (Figura 6B e 6C).

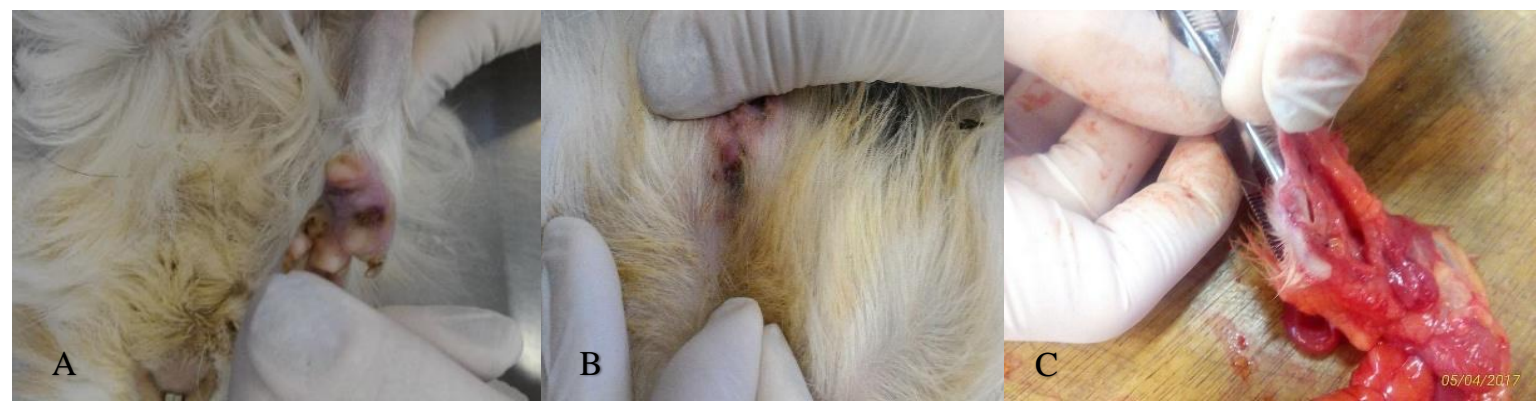

Figura 6. A. Pododermatite, B e C. Fístula Uretral.

Internamente notou-se nefrite intersticial crônica que levou ao choque toxêmico, no qual diversos órgãos dos variados conjuntos apresentaram congestão (Figura 7A e 7B).

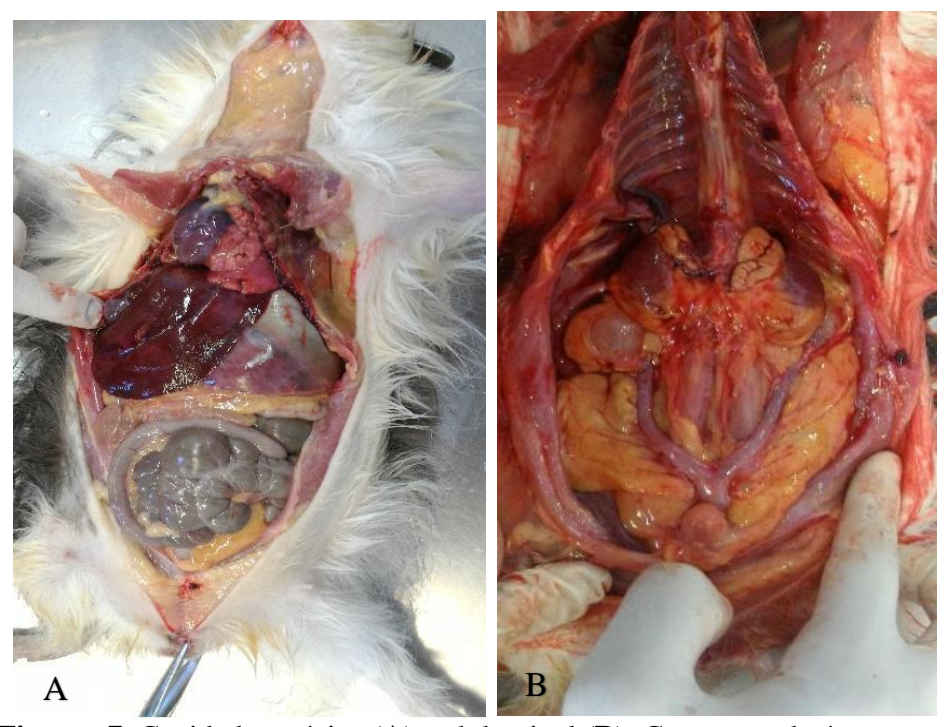

Figuras 7. Cavidade torácica (A) e abdominal (B): Congestão de órgãos

No exame microscópico foi possível identificar no rim glomerulonefrite, identificando a presença de linfócitos caracterizando a presença de uma doença com caráter crônico (Figura 8). 


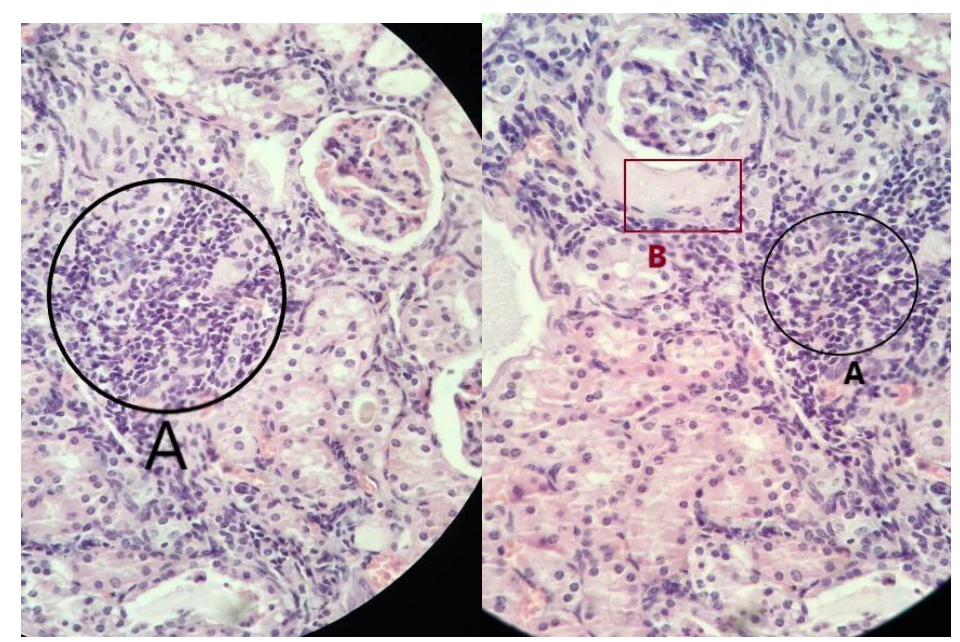

Figuras 8. Glomerulonefrite. A- Aglomerado de linfócitos e B - Cápsula de Bowman espessada com linfócitos ao redor. A presença de linfócitos caracteriza uma doença crônica no parênquima renal.

O cálculo que foi encaminhado para análise (Tabela 4), apresentava sua composição de carbonato de cálcio, oxalato de cálcio e fosfato triplo.

Tabela 4. Análise d0 cálculo de um porquinho-da-índia, fêmea, 4.8 anos, atendida na Clínica Escola Veterinária da Universidade de Guarulhos

\begin{tabular}{lll}
\hline Análise Física & Análise Química & \\
\hline Peso: $2,6 \mathrm{~g}$ & Carbonato: + & Oxalato: + \\
Dimensões: $2,3 \mathrm{~cm} \times 1,5 \mathrm{~cm}$ & Cálcio: + & Magnésio: + \\
Cor: Esbranquiçado & Fosfato: + & Amônio: + \\
Superfície: Lisa & Urato: - & \\
\hline Consistência: Pétrea & Cistina: - & \\
\hline Conclusão: & Carbonato de cálcio, Oxalato de cálcio e Fosfato triplo. \\
\hline
\end{tabular}

\section{Discussão}

O presente relato descreve um caso de urolitíase (presença de urólito em uretra caudal que é denominado uretrólito) em uma fêmea da espécie Cavia porcellus (porquinho-da-índia). A urolitíase é comum em porquinhos-da-índia, podendo acometer animais adultos a idosos, machos ou fêmeas com mais de dois anos e meio de idade (Furlaneto, 2017; Gonçalves, 2014; Hawkins et al., 2009). O paciente atendido na Clínica Escola Veterinária da Universidade de Guarulhos apresentava fatores de risco para ocorrência dessa doença, como a senilidade (animal de 4,8 anos de idade) e sedentarismo. O cálculo de dois $\mathrm{cm}$ foi retirado da uretra caudal de uma fêmea. Nos resultados de estudos de Hawkins et al. (2009), 40\% dos casos ocorreram em fêmeas, sendo que a maioria dos cálculos foi encontrada na vesícula urinária (45\% dos cálculos). Furlaneto (2017) refere que a vesícula urinária é a local mais comum para formar urólitos; porém, podem ser formados por todo trato urinário, incluindo rins, ureteres e também uretra.

A etiopatogenia da urolitíase em porquinho-da-índia não está definida; porém, fatores como $\mathrm{pH}$ urinário já ser de caráter alcalino predispondo a precipitação e formação de cristais, obesidade, ingestão inadequada de água, higiene inadequada da gaiola, falta de exercício, doença renal, suplementação mineral e vitamínica e a ingestão de alimentos com alto teor mineral, podem ser fatores contribuintes(Stieger et al., 2003). Segundo Gonçalves (2014), a suplementação de vitaminas e minerais também são fatores de risco, a vitamina $\mathrm{D}$ pode aumentar a excreção renal de cálcio por aumentar a absorção intestinal dele, e a vitamina $\mathrm{C}$ pode induzir a síntese de urólitos de oxalato de cálcio por hiperoxalúria.

Os sinais clínicos apresentados foram dor à palpação e vocalização, sinais também observados por Hawkins et al. (2009). Estes sinais dependem da localização quantidade e tamanho dos cálculos. Por serem presas na natureza, os porquinhos-da-índia tendem a mascarar sinais de dor ou desconforto, 
levando a percepção da doença tardiamente (Vella, 2012), o que pode ser observado no presente relato, visto que o proprietário relatou que o paciente havia expressado sinais de dor há um mês.

O diagnóstico se baseou em exames de hemograma, radiografia, ultrassonografia abdominal e foi indicado procedimento cirúrgico, assim como descrito por Martel-Arquette \& Mans (2016) e Furlaneto (2017). O exame radiográfico é um método que pode identificar a presença de cálculos em todo trato urinário, entretanto, o excesso de gás em estômago é um sinal de estase do trato gastrointestinal que pode dificultar a visualização, sendo causado por estresse e dor que causam os cálculos. Quando tem presença de gás exacerbada pode se optar pelo exame ecográfico para localizar lesões em outros órgãos, identificar anatomicamente o cálculo, determinando assim, o melhor acesso cirúrgico (Gonçalves, 2014). A avaliação do hemograma foi solicitada para determinar o risco anestésico, o estado do paciente, se havia infecção sistêmica e perda sanguínea, porém, a infecção e inflamação local não são totalmente descartadas, porque podem não levar a alterações em hemograma. Pela suspeita de neoplasia, pelo aumento de volume em região perivulvar solicitou-se o exame radiográfico do pulmão e ultrassonográfico abdominal para que pudesse apontar possíveis metástases.

Devido aos exames não indicarem a presença de infecção no caso em estudo, não foi realizado exame de urina e sedimento urinário, que permitiria avaliar a presença de infecção através da observação de elevado número de eritrócitos, leucócitos ou bactérias, com posterior cultura e antibiograma para determinar o agente, identificar tipos de cristais e instituir o tratamento adequado. Geralmente os cálculos em porquinhos-da-índia, não são tipicamente associados a infecções bacterianas (Hoefer, 2013). Para realizar a análise da urina, pode se obter a amostra por compressão manual cuidadosa (se feita sem o cuidado necessário pode predispor a rupturas ou presença de sangue), micção espontânea, cateterização ou cistocentese (cuidado com o ceco que possui elevado volume, se puder fazê-la guiada por ultrassom) (Gonçalves, 2014). A presença de hematúria na urina deve ser diferenciada de pigmentos alimentares ou por componentes sanguíneos, a tira de urina ou o esfregaço são exames que permitem diferenciá-los. Quando presente a hematúria pode significar atrito do cálculo com o trato urinário levando a um trauma da mucosa, inflamação, infecção ou neoplasia (Gonçalves, 2014).

O tratamento de eleição para urolitíase é a remoção cirúrgica, por uretrotomia, cistotomia, amputação do pênis em machos ou cistoscopia em fêmeas, sendo este um método pouco invasivo (Furlaneto, 2017; Hawkins et al., 2009; Martel-Arquette \& Mans, 2016). Não há nenhum tratamento clínico descrito eficaz para dissolução de urólitos em pequenos herbívoros (Hoefer, 2013), em fêmeas com cálculos pequenos, é possível removê-los com terapia intensiva ou podem ser acompanhados por exames periódicos de radiografias e tiras urinárias (Gonçalves, 2014; Johnson, 2013). Os cálculos vesicais podem não causar sintomatologia clínica de obstrução, porém também devem ser removidos por causarem cistite, dor e predispor à infecção e podendo migrar para a uretra e causar obstrução, tornando o quadro ainda mais grave que se não tratado leva à morte do animal, em fêmeas esse quadro de deslocamento é mais comum por possuírem uma uretra pélvica com diâmetro maior. Em quadros de obstruções, os pacientes possuem os sinais referidos anteriormente, além de distensão da bexiga, sinais de uremia (hipotermia, bradicardia, taquipneia, estupor ou coma), arritmia ventricular pela hipercalemia, alterações eletrolíticas (hiponatremia, hipercalemia, hipocloremia) e até mesmo convulsões (Gonçalves, 2014).

O tratamento suporte deve ser instituído com antibioticoterapia, quando houver infecções ou para prevenção, fluidoterapia, controle de dor, suplementação de vitamina C (Furlaneto, 2017). Ainda é necessário manejo nutricional com redução do número de fibras e teor de cálcio, estimular a ingestão de água, optar preferencialmente por bebedores de mamilo (Furlaneto, 2017; Pessoa, 2007). Pododermatite, míase e dermatite de períneo podem ser possíveis complicações relacionadas aos urólitos (Gonçalves, 2014). Paciente apresentava pododermatite nos quatro membros que poderia ser uma complicação da urolitíase ou do sedentarismo.

Os cálculos podem ser constituídos por carbonato de cálcio, fosfato de cálcio, oxalato de cálcio, cistina, urato de amônio, estruvita (fosfato de amônio e magnésio), calcita, podem ser puros ou mistos (Furlaneto, 2017; Hawkins et al., 2009). No resultado da análise de cálculo foi possível visualizar carbonato de cálcio que foi parcialmente compatível com os estudos realizados por Hawkins et al. (2009), em que a maioria dos cálculos em porquinhos-da-índia eram compostos por $100 \%$ de carbonato de cálcio, apesar de detectar outros tipos de cristais em sedimentos de urina, porém, observamos outros componentes como o fosfato triplo e o oxalato de cálcio no próprio urólito enviado 
para análise. O prognóstico é reservado pela possibilidade de recidivas (Martel-Arquette \& Mans, 2016). Quando instituída a cirurgia o prognóstico reservado é atribuído ao pós-operatório que deve ser cuidadoso.

Visando a alta incidência dessa patologia na clínica veterinária de porquinhos-da-índia, deve-se ressaltar a importância de cuidados preventivos e acompanhamento clínico rotineiramente, fornecendo dieta adequada e manejo correto.

\section{Considerações finais}

O relato apresentado neste trabalho foi diagnosticado com um aumento de volume em região perineal sendo sugestivo de formação tumoral, ao realizar a cirurgia foi diagnosticado urolitíase e o tratamento de escolha foi a remoção cirúrgica. Sabendo-se que a recuperação de porquinhos-da-índia após procedimentos cirúrgicos é um processo delicado, que exige muita atenção e cuidados. $\mathrm{O}$ paciente formou uma fístula de comunicação entre a uretra e o períneo durante o pós-operatório e a recuperação cirúrgica. $\mathrm{O}$ processo crônico da doença renal pode ter dificultado a recuperação cirúrgica levando o paciente ao choque e a óbito. Vale ressaltar a importância do manejo correto da dieta para os porquinhos-da-índia com alimentos com baixos níveis de cálcio, como forma preventiva para esta patologia e suas consequências e também o incentivo ao consumo de água, evitar sedentarismo do paciente, deixando o ambiente mais ativo com enriquecimento ambiental e sempre buscar orientação de um médico veterinário.

\section{Referências bibliográficas}

Dias, C. D. (2016). Urolitíase numa população de macropus rufus e macropus rufogriseus do Jardim Zoológico de Barcelona. Master of Science, Universidade Lusófona de Humanidades e Tecnologias, Lisboa, Portugal.

Eurell, J. A. \& Frappier, B. L. (2012). Histologia Veterinária de Dellmann (Vol. 1). Rio de Janeiro, Brasil: Guanabara Koogan.

Furlaneto, B. E. (2017). Urolitíase vesical em Cavia porcellus (porquinho-da-Índia) e adenocarcinoma uterino em Oryctolagus cuniculus (coelho doméstico). Master of Science, Universidade Tuiuti do Paraná, Curitiba, Paraná, Brasil.

Gonçalves, I. S. V. (2014). Medicina e cirúrgia de animais exóticos. Porto, Portugal: Universidade do Porto.

Hawkins, M. G., Ruby, A. L., Drazenovich, T. L. \& Westropp, J. L. (2009). Composition and characteristics of urinary calculi from guinea pigs. Journal of the American Veterinary Medical Association, 234(2):214-220.

Hoefer, H. L. (2013). Excellence in exotics: Case report: urolithiasis in a female Guinea pig. Compendium Continious Education, 35(2):E5-E5.

Johnson, D. H. (2013). The Critical Exotic Surgical Patient: Procedures and Surgeries. International Veterinary Emergency and Critical Care Symposium.

Latney, L. T. \& Donnelly, T. M. (2013). Urolithiasis. In J. Mayer \& T. Donnelly (Eds.), Clinical veterinary advisor, birds and exotic pets (pp. 282-283). USA: Edit: Saunders.

Martel-Arquette, A. \& Mans, C. (2016). Urolithiasis in chinchillas: 15 cases (2007 to 2011). Journal of Small Animal Practice, 57(5):260-264.

Pessoa, C. A. (2007). Rodentia-Roedores de Companhia (Hamster, Gerbil, Cobaia, Chinchila e Rato) (Vol. 1). São Paulo: Roca.

Stieger, S. M., Wenker, C., Ziegler-Gohm, D. \& Flückiger, M. (2003). Ureterolithiasis and papilloma formation in the ureter of a guinea pig. Veterinary Radiology \& Ultrasound, 44(3):326-329.

Vella, D. (2012). Emergency presentations of exotic mammal herbivores. Journal of Exotic Pet Medicine, 21(4):293-299.

Recebido: 20 de janeiro, 2019.

Aprovado: 11 de fevereiro, 2019

Publicado: 19 de março, 2019.

Licenciamento: Este artigo é publicado na modalidade Acesso Aberto sob a licença Creative Commons Atribuição 4.0 (CC-BY 4.0), a qual permite uso irrestrito, distribuição, reprodução em qualquer meio, desde que o autor e a fonte sejam devidamente creditados. 